\title{
La competencia temática en la formación de traductores de textos jurídicos en la combinación lingüística francés/español
}

\author{
GuAdalupe Soriano Barabino \\ Universidad de Granada \\ barabino@ugr.es
}

Recibido: 6 de diciembre de 2012

Aceptado: 27 de febrero de 2013

\section{RESUMEN}

El artículo que presentamos pretende acercar a los estudiantes que se enfrentan por primera vez a la traducción de textos jurídicos, en la combinación lingüística francés/español, al contenido temático que rodea la traducción de textos con origen o destino en los ordenamientos jurídicos de Francia y España, con objeto de desarrollar la competencia temática (Kelly 1999, 2002, 2005). Esta necesidad surge principalmente de las divergencias entre ordenamientos jurídicos, así como del recelo por parte de los estudiantes al acercarse a una disciplina que les suele provocar rechazo.

Palabras clave: traducción de textos jurídicos, competencia temática, ordenamientos jurídicos francés y español.

Subject area competence in legal translation training in the French/Spanish language combination

\begin{abstract}
This paper aims to bring students who are facing for the first time translation of legal texts, in the French/Spanish language combination, closer to the thematic content surrounding the translation of legal texts originating or targeting the Spanish or French legal systems, as a means to develop subject area competence (Kelly 1999, 2002, 2005). This need arises mainly from the divergences existing between legal systems and from the fear showed by students who are facing a discipline they usually reject.
\end{abstract}

Keywords: translation of legal texts, subject area competence, French and Spanish legal systems. 
Sumario: 1. Introducción. 2. ¿Por qué es necesario un estudio de Derecho Comparado como marco en el que situar la Traducción Jurídica? 3. La tradición jurídica romano-germánica. 4. Los ordenamientos jurídicos francés y español. 5. Conclusiones.

\section{Introducción}

No son pocos los autores que se han detenido en analizar y comparar diferencias entre ordenamientos jurídicos a fin de establecer una serie de parámetros que, en el marco del Derecho Comparado, acerquen la ciencia jurídica a los traductores, ya sean profesionales o en período de formación. Sin embargo, la mayor parte de dichos estudios, salvo contadas excepciones, entre las que podemos citar a Valderrey (2004), se han llevado a cabo dentro de combinaciones lingüísticas que a priori podrían parecernos más distantes que la de francés-español. Así, autores como Acuyo (2004), Calvo (1999, 1999-2000, 2002) o Soriano (2000, 2002a, 2002b, 2004), entre otros, han realizado estudios de Derecho Comparado como base del análisis traductológico de diferentes áreas del Derecho en la combinación lingüística inglés-español. Quizás encontremos la razón para haber desatendido la combinación lingüística a la que hacíamos referencia al principio (francés-español) en que, al ser los ordenamientos jurídicos francés y español parte de la misma tradición jurídica, la de derecho de origen romano-germánico, ello nos incite a pensar que las diferencias entre ambos son menores y que, por tanto, la traducción entre ambos ordenamientos jurídicos no debe suponer ningún problema al traductor.

Sin embargo, dicha cercanía entre ordenamientos jurídicos no es óbice para llegar a tal conclusión y, de hecho, el traductor novel que posee dicha combinación lingüística encuentra las mismas dificultades en cuanto a la comprensión de conceptos jurídicos básicos que aquél que posee cualquier otra combinación lingüística. Por ello, nos proponemos en el presente capítulo llevar a cabo un acercamiento a algunas cuestiones básicas de ambos ordenamientos, limitándonos en este caso a Francia y España. Para ello, nos basaremos principalmente en la organización de la justicia en uno y otro ordenamiento jurídico.

El hecho de centrarnos en este aspecto y no en otro se debe principalmente a una necesidad detectada como docente de Traducción Jurídica. Al enfrentarse a la Traducción Jurídica por primera vez, los estudiantes suelen tener una serie de temores relacionados con una supuesta dificultad de la asignatura. A medida que los estudiantes van conociendo la base teórica y conceptual sobre la cual se asienta la traducción de textos jurídicos esos temores van desapareciendo porque lo desconocido pasa a ser conocido. Si obviamos este aspecto teórico básico -la organización de la justicia, en tanto que organización del conocimiento en la cultura jurídica de que se trate-, estamos saltando el primer escalón de la escalera de conocimiento que compone cada ordenamiento jurídico y, por tanto, dificultando la adquisición de una serie de conocimientos teóricos básicos por parte de los estudiantes de Traducción Jurídica.

El análisis que presentamos a continuación se origina a partir de una serie de materiales utilizados en el aula de Traducción Jurídica en la Licenciatura en Tra- 
ducción e Interpretación de la Universidad de Granada, sobre los que los estudiantes deben trabajar para adquirir los conocimientos conceptuales básicos que les van a permitir un primer acercamiento al derecho en los dos países indicados. El objetivo de estas primeras actividades no es traducir sino sentar las bases temáticas y conceptuales imprescindibles para el análisis textual previo a la traducción y permitir que sean los propios estudiantes los que, a partir de dicha adquisición conceptual, se atrevan a iniciar el proceso traductor de textos jurídicos en la combinación lingüística y jurídica indicada.

Este análisis de Derecho Comparado se ubica dentro del conocimiento derivado de la subcompetencia temática, elemento de la competencia traductora (Kelly 1999, $2002,2005)$, fundamental en la formación de traductores y está orientado, por tanto, a aquéllos que se enfrentan por primera vez a la traducción de textos jurídicos dentro de la combinación lingüística francés-español.

\section{2. ¿Por qué es necesario un estudio de Derecho Comparado como marco en el que situar la Traducción Jurídica?}

La Didáctica de la Traducción defiende la necesidad de que el traductor adquiera, a lo largo de su formación, una serie de destrezas, conocimientos y habilidades que le permitan desarrollar su competencia traductora. La competencia traductora se compone de una serie de subcompetencias entre las cuales se encuentra la competencia temática (Kelly 1999, 2002, 2005). En traducción jurídica, la competencia temática viene constituida, en gran medida, por el conocimiento de los ordenamientos jurídicos en los que se enclavan los textos (origen y meta) que forman parte del proceso traductor. Pero la adquisición de la competencia temática en traducción jurídica no es algo precisamente fácil debido, principalmente, a las divergencias entre ordenamientos jurídicos. Así, Pelage afirma en este sentido que:

La mise en relation de deux systèmes de droit est effectivement un problème pour le traducteur. Il l'est aussi pour le juriste. Cette constatation nous amène à comparer les systèmes de droit non plus à d'autres systèmes sociaux mais aux systèmes scientifiques.

Un mathématicien, un physicien, un chimiste, qui a étudié sa discipline aux EtatsUnis et a appris à résoudre des problèmes d'une certaine nature, pourra résoudre les mêmes problèmes au Japon ou en Suède. En bref, ses connaissances techniques sont directement transposables dans un autre milieu. Par contre, un juriste spécialisé dans les successions en droit français ne peut pas donner une consultation sur une question de succession en droit espagnol, même s'il connaît le castillan, à moins qu'il n'ait étudié les deux systèmes de droit: ses connaissances techniques ne sont pas directement transposables dans un autre milieu. C'est là une conséquence directe du lien fondamental entre droit et société (Pelage 2001: 25).

De ahí la necesidad de comenzar todo acercamiento a la traducción jurídica por un estudio previo de las culturas jurídicas en las que se enmarca el proceso traductor. 


\section{La tradición jurídica romano-germánica}

Tanto el ordenamiento jurídico francés como el español se enmarcan en la tradición jurídica romano-germánica. Pertenecen a dicha tradición jurídica todos los ordenamientos jurídicos que se formaron sobre la base del derecho de la antigua Roma, aunque una evolución de más de mil años ha cambiado tanto el derecho sustantivo como las reglas de procedimiento desde los tiempos de Augusto o de Justiniano.

Actualmente, la familia de derecho romano-germánico se encuentra repartida por todo el mundo, desde diversos países de la Europa occidental hasta Japón o Indonesia. Sin embargo, no podemos decir que el derecho en estos países comparta tantas similitudes a primera vista como pudiéramos pensar por el hecho de que todos los ordenamientos jurídicos sean de origen romano-germánico sino que dentro de esta familia es posible encontrar subgrupos, tales como el derecho germánico, el escandinavo o el de los países de Latinoamérica, entre otros. Parte de esta grandiosa expansión se debe a la colonización y parte a la codificación, técnica jurídica globalmente adoptada por los derechos romanistas durante el siglo XIX, y que facilitó su expansión. Además, cada ordenamiento jurídico ha evolucionado de acuerdo con la sociedad en la que se inscribe y de ahí que existan enormes divergencias hoy día entre unos y otros.

En cuanto a cómo se estructura el derecho, en los ordenamientos jurídicos de todos los países de la familia de derecho romano-germánico encontramos la división entre Derecho Público y Derecho Privado. Ésta es una clara característica de dichos ordenamientos y se basa en la distinción entre la esfera de relaciones entre los que gobiernan y los gobernados, basándose en que el interés público no puede tener el mismo peso que el interés de los individuos.

Otra característica común a todos los ordenamientos jurídicos en esta familia es que, tanto en el caso del Derecho Público como en el del Derecho Privado, encontramos las mismas ramas del conocimiento en todos los países o regiones en los que el derecho se inscribe dentro de esta familia. Esta semejanza conceptual deriva del hecho de que, durante siglos, la ciencia del Derecho en toda Europa continental se basó en la misma enseñanza, cuyas raíces procedían del Derecho Romano y del Derecho Canónico.

Respecto a las fuentes del derecho, las normas promulgadas por el Estado, es decir, la legislación -así como otras normas con valor reglamentario que emanan, en ciertos casos, del poder ejecutivo- constituyen actualmente la fuente primaria, casi exclusiva, del derecho en los países de la familia romano-germánica. Todos los países que se inscriben en esta tradición jurídica cuentan con constituciones, leyes promulgadas y códigos. La costumbre, por su parte, desempeña un papel secundario al de la legislación en estos países. Sin embargo, en ocasiones es necesario recurrir a la costumbre para clarificar las ideas de los legisladores y así poder comprender la legislación.

La jurisprudencia, la doctrina y los principios generales del derecho son elementos que inspiran la actuación de todos aquellos implicados en el hacer jurídico, pero no constituyen hoy día fuentes del derecho en los países cuyo ordenamiento 
jurídico se inscribe en la familia romano-germánica. Respecto a la jurisprudencia, el papel creativo de las decisiones judiciales se esconde en la práctica totalidad de las ocasiones bajo la esfera de la «interpretación» de la legislación. La doctrina, por su parte, constituye para algunos autores (David, 1964) una fuente viva del derecho, en el sentido en que crea el vocabulario jurídico y las ideas en las que se basa el legislador. Finalmente, en cuanto a los principios generales del derecho, su papel fundamental consiste en resaltar el hecho de que en la familia de derecho romano-germánico existe una subordinación del derecho a la justicia, tal y como ésta se concibe en un momento y período dados, y que esta tradición jurídica no consiste exclusivamente en un conjunto de normas legislativas.

\section{Los ordenamientos jurídicos francés y español}

Tras haber realizado esta introducción a la tradición jurídica romano-germánica, nos detendremos a continuación en analizar algunas de las peculiaridades de los ordenamientos jurídicos francés y español, respectivamente. Para ello, nos centraremos principalmente en la organización de la justicia tanto en Francia como en España y, en el personal al servicio de la justicia. El fin de dicho estudio es, como ya ha sido señalado, realizar una primera aproximación a la realidad jurídica de dos países como Francia y España a aquéllos que comienzan a formarse en la traducción de textos jurídicos pero no ofrecer soluciones de traducción. Sin embargo, este análisis podrá servir de base para realizar una comparación entre ambos ordenamientos en cuanto a los aspectos señalados, y poder establecer una serie de equivalencias de cara a la traducción de textos jurídicos ${ }^{1}$.

\subsection{El ordenamiento jurídico español}

En el ordenamiento jurídico español, como hemos señalado anteriormente, al igual que en los demás ordenamientos jurídicos originados a partir del Derecho Romano, existe una división interna en el seno del derecho que distingue entre Derecho Público y Derecho Privado. La base de dicha distinción radica, fundamentalmente, en la diferente jurisdicción para unas y otras materias.

Así, el Derecho Público tutela, de forma directa, los intereses públicos y generales, mientras que el Derecho Privado, si bien su fin sigue siendo la protección de los intereses comunes de la sociedad, lleva a cabo dicha protección por medio de la tutela de los intereses particulares. De este modo, el Estado se erige como protagonista del Derecho Público, mientras que en el caso del Derecho Privado, tanto los

\footnotetext{
1 No ofrecemos soluciones de traducción porque consideramos que la búsqueda de equivalentes se ve influida por diversos factores, entre los cuales se encuentran el encargo de traducción o la situación comunicativa y cabe que el mismo término o institución jurídica pueda ser traducida de una u otra forma en función de los criterios que acaban de ser indicados.
} 
individuos -personas físicas- como las personas jurídicas son sujetos de derecho. Debido a ello, las normas de Derecho Público son imperativas y conllevan una relación de subordinación, mientras que las normas de Derecho Privado contienen lo que se conoce como normas de coordinación de las relaciones jurídicas a las que se someten las personas, físicas o jurídicas.

Ambas ramas del derecho se subdividen principalmente por materias, algunas de las cuales son, por ejemplo, el Derecho Administrativo o el Derecho Penal dentro del Derecho Público, y el Derecho Mercantil o el Derecho Civil en la esfera del Derecho Privado, en tanto que regulan las relaciones jurídicas de las personas.

\begin{tabular}{||l|l|l||}
\hline & DERECHO PÚBLICO & DERECHO PRIVADO \\
\hline OBJETO & $\begin{array}{l}\text { Tutela de forma directa intereses públicos y } \\
\text { generales }\end{array}$ & Tutela intereses particulares \\
\hline PROTAGONISTA & $\begin{array}{l}\text { El Estado y los entes que representan al } \\
\text { poder público }\end{array}$ & Personas físicas y jurídicas \\
\hline NORMAS & Imperativas & De coordinación \\
\hline MATERIAS & $\begin{array}{l}\text { Derecho administrativo } \\
\text { Derecho penal, etc. }\end{array}$ & $\begin{array}{l}\text { Derecho mercantil } \\
\text { Derecho civil, etc. }\end{array}$ \\
\hline
\end{tabular}

\subsection{El ordenamiento jurídico francés}

Si bien el ordenamiento jurídico francés también se divide internamente en dos ramas, éstas no corresponden a las mencionadas en el caso del ordenamiento jurídico español (aunque el ordenamiento jurídico francés también reconoce la división entre Derecho Público y Derecho Privado, no es esta diferencia la que inspira la división interna del mismo). En Francia el derecho se divide en una rama judicial (ordre judiciaire) y en una rama administrativa (ordre administratif). Esta división se basa en el principio de separación de poderes recogido en la ley francesa de 16-24 de agosto de 1790, que prohíbe a los jueces de la rama judicial en su artículo 13 «troubler de quelque manière que ce soit les opérations des corps administratifs, ni citer devant eux les administrateurs en raison de leurs fonctions》.

El ordre judiciaire está compuesto por jurisdicciones civiles y penales. De modo similar a lo que ocurre en el ordenamiento jurídico español, las jurisdicciones civiles conocen de los litigios entre personas (físicas o jurídicas) y las penales reprimen las infracciones cometidas y sancionadas por la ley. Es aquí, por tanto, donde vemos la división entre Derecho Público y Privado a la que hacíamos referencia anteriormente. El ordre administratif, por su parte, es el encargado de intervenir en aquellos conflictos entre administraciones o entre el Estado y los particulares. 


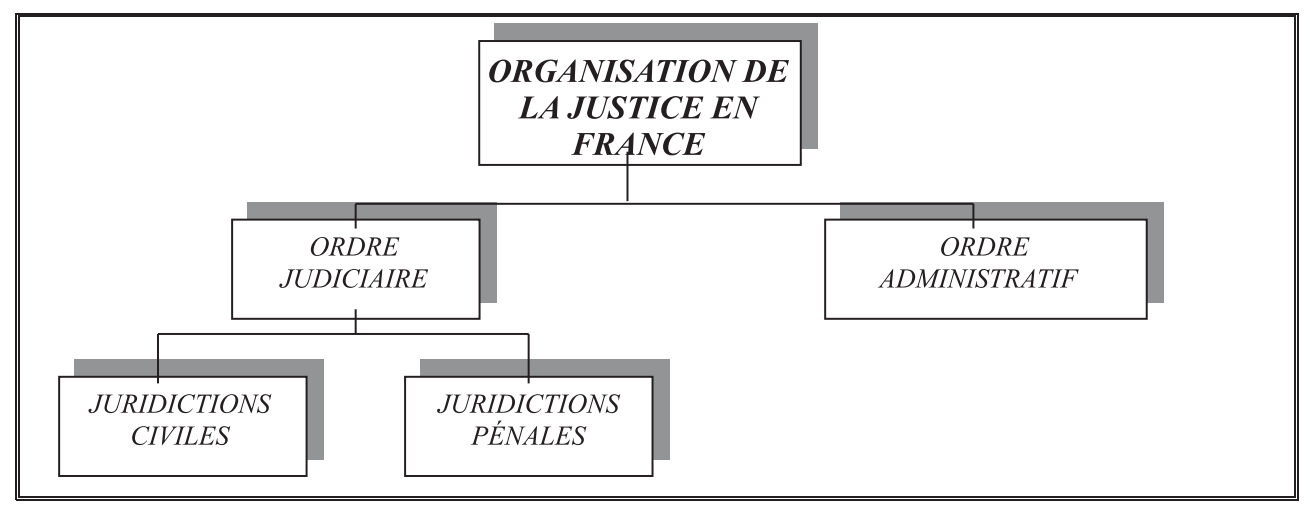

\subsection{El personal al servicio de la justicia en España}

El personal al servicio de la administración de la justicia en España puede dividirse en dos grandes categorías. Por una parte, nos encontramos el personal que integra los órganos de la Administración de Justicia, donde podemos diferenciar entre personal juzgador y no juzgador existiendo, dentro de los mismos, diferentes categorías. Así, dentro del personal juzgador cabe distinguir entre el personal juzgador de carrera (magistrados del Tribunal Supremo, magistrados y jueces) o el personal juzgador que no pertenece a la carrera judicial (magistrados suplentes y jueces sustitutos así como los jueces de paz y sus sustitutos).

La diferencia entre juez y magistrado radica en que, siendo ambos miembros de la carrera judicial, reciben la denominación de magistrado quienes ejercen su función en Audiencias y Tribunales, así como en juzgados de capital de provincia o de algunas poblaciones importantes. Los jueces constituyen la categoría inferior dentro de la carrera judicial y ejercen sus funciones en juzgados que no sean de capital de provincia o de poblaciones importantes.

El personal no juzgador, por su parte, está compuesto por los secretarios judiciales, cuyas funciones principales consisten en el ejercicio de la fe pública judicial, la formación de autos y expedientes, la organización, gestión, inspección y dirección del personal en aspectos técnicos procesales, la dación de cuenta o el impulso del proceso, entre otras; y por el cuerpo de funcionarios al servicio de la Administración de Justicia, dentro de los cuales cabe diferenciar entre los cuerpos generales y los cuerpos especiales.

Los primeros, el cuerpo de Gestión Procesal y Administrativa, el cuerpo de Tramitación Procesal y Administrativa y el cuerpo de Auxilio Judicial, desempeñan tareas de carácter procesal y corresponden a los anteriores Oficiales, Auxiliares y Agentes de Justicia (la denominación cambió a raíz de la entrada en vigor de la Ley 19/2003, de 23 de diciembre, de modificación de la Ley Orgánica 6/1985, de 1 de julio, del Poder Judicial). La diferencia entre los tres cuerpos radica principalmente en la especialización de las funciones atribuidas a uno y otro. 
Los cuerpos especiales, por su parte, tienen por cometido el desempeño de funciones objeto de una profesión o titulación específica y son el cuerpo de Médicos Forenses, el cuerpo de Facultativos del Instituto Nacional de Toxicología y Ciencias Forenses, el cuerpo de Técnicos Especialistas del Instituto Nacional de Toxicología y Ciencias Forenses y el cuerpo de Ayudantes de Laboratorio del Instituto Nacional de Toxicología y Ciencias Forenses.

Por otra parte, existen los órganos cooperadores de la Administración de Justicia, entre los que se encuentra el Ministerio Fiscal, los abogados y procuradores, la policía judicial o los abogados del Estado.

Tanto los abogados como los procuradores son personas técnicas en derecho que defienden a las partes y la principal diferencia entre ambos radica en la función que tienen atribuida en el proceso. La función genérica del abogado consiste en ejercer profesionalmente la dirección y defensa de las partes o, en su caso, el asesoramiento jurídico, no sólo en el proceso, sino también extrajudicialmente (González Montes 1993: 215). El Consejo General de la Abogacía Española es el órgano representativo, coordinador y ejecutivo superior de los Colegios de Abogados.

En cuanto a los procuradores, su función consiste en la representación técnica de las partes en todos los procesos. A diferencia del abogado, que se ocupa de la defensa, el procurador es un órgano de representación de las partes en el proceso con exclusividad. Al igual que ocurría en el caso de la Abogacía, existe, a nivel nacional, el Consejo General de los Colegios de Procuradores de los Tribunales de España.

El Ministerio Fiscal, por su parte, tiene por misión promover la acción de la justicia en defensa de la legalidad, de los derechos de los ciudadanos y del interés público tutelado por la ley, de oficio o a petición de los interesados, así como velar por la independencia de los tribunales y procurar ante éstos la satisfacción del interés social.

Respecto a los abogados del Estado, éstos se encargan de la representación y defensa del Estado, de sus organismos autónomos, así como la representación y defensa de los órganos constitucionales, cuyas normas internas no establezcan un régimen especial propio.

Vemos a continuación un gráfico en el que se representan las diferentes profesiones que acabamos de analizar: 


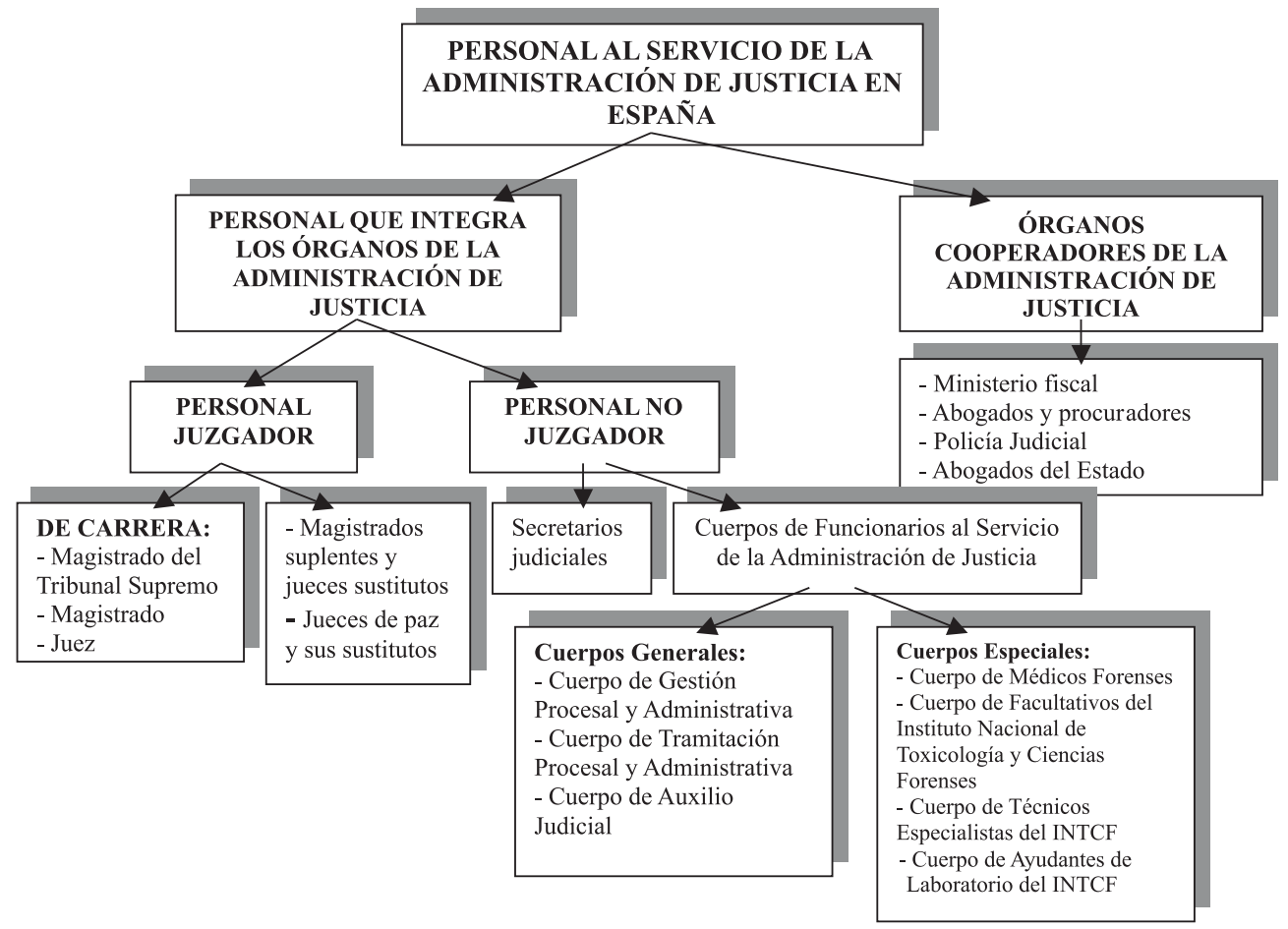

\subsection{El personal al servicio de la justicia en Francia}

En Francia cabe hablar de una división, en cuanto a la profesión judicial, que diferencia entre aquellas personas que forman la magistrature y las que colaboran con dicho cuerpo de una forma u otra. Dentro de la magistrature existen dos grupos diferenciados de magistrats: los magistrats du siège y los magistrats du parquet (Cornu, 2007). Entre las personas que colaboran en la administración de la justicia cabe incluir a los avocats, los avoués, los avocats aux conseils, los greffiers, o los huissiers de justice. Nos detendremos a continuación en cada uno de ellos.

La magistrature se divide, en Francia, en les magistrats du siège (ou assis) y les magistrats du parquet (ou debout). Los primeros son los encargados de dictar las resoluciones judiciales (juges) y dentro de los segundos cabe diferenciar entre los procureurs, los avocats généraux y los substituts. Al igual que ocurre en derecho español, los jueces son los encargados de velar por el correcto desarrollo del proceso y son los que dictan las resoluciones judiciales conforme a Derecho. Existen numerosos tipos de jueces en Francia en función del tribunal en el que ejercen, de la materia en la que están especializados o de la fase del procedimiento en la que intervienen. Algunos ejemplos son el juge aux affaires familiares en el tribunal de grande instance, especializado en cuestiones de separación y divorcio y sus efectos, el juge des enfants, también en el mismo tribunal, especializado en cuestiones de 
menores en el ámbito civil, el juge de l'exécution, quien interviene en asuntos relacionados con la ejecución de decisiones judiciales, también en el tribunal de grande instance, o el juge des tutelles, en el tribunal d'instance, encargado de conocer de casos de tutelas o guarda de menores.

Al igual que ocurriera en derecho español con los Jueces de Paz, en el ordenamiento jurídico francés existen una serie de jueces legos o no profesionales como son los jueces del tribunal de commerce, que son comerciantes, o los jurados que componen la cour d'assises.

Dentro de los magistrats du parquet encontramos, como ya hemos señalado, a los procureurs. Éstos, al contrario de lo que pudiéramos pensar a primera vista, no tienen nada que ver con los procuradores españoles sino más bien con el Ministerio Fiscal o Público, ya que su función consiste en representar los intereses de la sociedad y velar por el respeto del orden público y de la aplicación de la ley. Dentro de los procureurs, cabe diferenciar entre el Procureur de la République, cabeza del ministerio público en el tribunal de grande instance y el Procureur General, cabeza del ministerio público en la Cour d'Appel o en la Cour de Cassation. Junto a los procureurs son también magistrats du parquet los avocats généraux que, lejos de ser abogados como podría incitarnos a pensar su nombre, no son sino los representantes del ministerio público en las Cour de Cassation, Cour de Comptes, cours d'appel y cours d'assises. Finalmente, los substituts son también representantes del ministerio público a los que el Procureur de la République delega una serie de competencias principalmente en el ámbito penal.

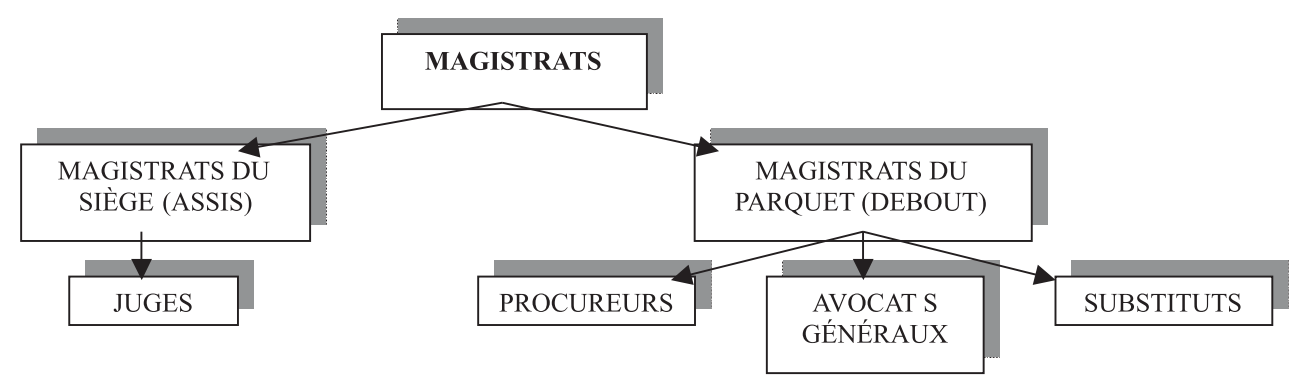

Dentro del grupo de personas que cooperan con la Administración de Justicia en Francia nos encontramos, en primer lugar, con aquellas profesiones cuya labor es defender y representar los intereses de las partes: avocats, avoués y avocats aux conseils. Los avocats informan a sus clientes acerca de sus derechos y obligaciones, así como del procedimiento a seguir. Asimismo, son los encargados de representar los intereses de sus clientes ante la justicia. La intervención de un avocat no siempre es obligatoria sino que depende tanto del asunto en cuestión como de la jurisdicción competente para conocer del mismo. Los avocats se organizan de forma corporativa en torno a los barreaux u ordres. La función del avocat se encuentra muy cercana a la de su equivalente funcional en España, el abogado. 
Los avoués ${ }^{2}$, por su parte, son profesionales que representan a las partes ante las cours d'appel. Los avocats conservan en este caso su papel de consejero, pero son los avoués los que llevan a cabo los actos necesarios para que se desarrolle el procedimiento, y su intervención es obligatoria en la mayoría de los casos que se llevan ante las cours d'appel. Al igual que en el caso de los avocats, existe un órgano que reúne a los avoués, las compagnies. Los representantes de cada compagnie forman la Chambre nationale des avoués.

Los avocats aux conseils son avocats que intervienen en la Cour de Cassation y en el Conseil d'État. En estos tribunales, en los que no se juzga ya sobre el fondo sino que se casan (o no) decisiones tomadas por tribunales inferiores, el papel de los avocats aux conseils consiste en presentar observaciones escritas sobre el procedimiento y en argumentar acerca de cuestiones de derecho.

Tanto los greffiers como los huissiers son profesionales que trabajan codo a codo con los magistrats. Los greffiers son los encargados de levantar acta y de dar fe de todos los actos que se llevan a cabo durante el procedimiento. Asimismo, asisten a los magistrats en la preparación de los casos, dirigen los servicios administrativos de la magistrature y son los responsables de su funcionamiento.

Los huissiers de justice, por su parte, son los encargados de llevar a cabo una serie de actos, tales como entregar notificaciones o asegurar la ejecución de las resoluciones judiciales. Asimismo, son los encargados de realizar las comprobaciones que servirán de prueba en un juicio.

\section{Conclusiones}

De lo expuesto, no cabe más que volver a insistir en la importancia que reviste el que el traductor en período de formación en Traducción Jurídica posea, al menos, una serie de nociones básicas acerca de los ordenamientos jurídicos con los que va a trabajar. Las ideas que acabamos de exponer no resuelven problemas de traducción en sí pero quieren servir de base conceptual, a partir de la cual el traductor puede realizar comparaciones específicas de términos o instituciones, y hallar equivalentes según las necesidades del encargo de traducción de que se trate en cada momento. Si no contamos con esta conceptualización previa, el traductor puede cometer errores tan graves ( $\mathrm{y}$ tan corrientes, por otra parte, durante el período de formación) como traducir, por ejemplo, «avocat general» por «abogado general», «magistrat» por «magistrado» o «procureur» por «procurador».

Cabe indicar, por otra parte, que debido al período de formación al que se dirige nuestro análisis, éste es sin duda bastante elemental, con lo que relegamos una mayor exhaustividad a otros estudios destinados a diferentes fases formativas.

${ }^{2}$ La profesión de avoué desaparació el 1 de enero de 2012, en virtud de la ley 25 de enero de 2011. Sin embargo, consideramos interesante tratarla aquí debido a que los traductores deben, a menudo, enfrentarse a textos originados en el pasado. 
Calvo, E., La asimetría procesal entre los procedimientos de separación y divorcio en los sistemas irlandés y español. Proyecto de fin de carrera. Facultad de Traducción e Interpretación. Universidad de Granada 1999.

CALVO, E., «La asimetría procesal entre los procedimientos de separación y divorcio en los sistemas jurídicos irlandés y español: la traducción jurídica», Sendebar 10/11 (19992000), 261-78.

CALVO, E., «La influencia de la asimetría procesal en la traducción jurídica: procedimientos de separación y divorcio en Irlanda y España», en: WAY, C. (ed.), Puentes 2 (2002), 37-52.

Connu, G., Vocabulaire juridique. Paris: PUF 2007.

DAVID, R., Les grands systèmes de droit contemporains. Paris: Dalloz 1964.

González Montes, J. L., Instituciones de Derecho Procesal. Tomo I: La jurisdicción y sus órganos. $3^{\mathrm{a}}$ ed. Madrid: Tecnos 1993.

Kelly, D., Proyecto docente. Universidad de Granada [Inédito] 1999.

KELLY, D., «La competencia traductora: bases para el diseño curricular», Puentes 1 (2002), 9-20.

Kelly, D., A Handbookfor Translator Trainers. A Guide to Reflective Practice. Manchester: St Jerome 2005.

Ley Orgánica del Poder Judicial (LOPJ). Ley Orgánica 6/1985, de 1 de julio, del Poder Judicial.

LEY 19/2003, de 23 de diciembre, de modificación de la Ley Orgánica 6/1985, de 1 de julio, del Poder Judicial.

Pelage, J., Elements de traductologie juridique. Application aux langues romanes. París: s.e. 2001.

Socorro, K., La traducción comercial: un modelo didáctico para la traducción de documentos mercantiles del comercio internacional (inglés-español). Tesis doctoral. Universidad de Las Palmas 2002.

SORIANO, G., La guarda de menores en España e Inglaterra y País de Gales: análisis previo a la traducción. Proyecto de fin de carrera. Facultad de Traducción e Interpretación. Universidad de Granada 2000.

SORIANO, G., Estudio de derecho comparado entre España e Irlanda como fase previa a la traducción de un expediente de crisis matrimonial. Proyecto de Investigación, Facultad de Traducción e Interpretación. Universidad de Granada 2002.

SORIANO, G., «Incongruencia terminológica y equivalencia funcional en traducción jurídica: la guarda de menores en España e Inglaterra y Gales», en: WAY, C. (ed.), Puentes 2 (2002), 53-60.

SORIANO, G., La traducción de expedientes de crisis matrimoniales entre España e Irlanda: un estudio jurídico-traductológico. Tesis doctoral. Universidad de Granada 2004.

VALDERREY, C., Análisis descriptivo de la traducción jurídica (francés-español). Aportes para una mayor sistematización de su enseñanza. Salamanca: Ediciones Universidad de Salamanca 2004. 